\title{
Without up to date pest thresholds sustainable agriculture is nothing but a pipe-dream
}

\author{
by Leather, S.R. and Atanasova, D.
}

Copyright, Publisher and Additional Information: This is the author accepted manuscript. The final published version (version of record) is available online via Wiley.

Please refer to any applicable terms of use of the publisher.

DOI: $\underline{\text { http://dx.doi.org/10.1111/afe.12244 }}$ 


\title{
Without up to date pest thresholds sustainable agriculture is nothing but a pipe-dream
}

\author{
Simon R Leather ${ }^{1}$ \& Daniela Atanasova²
}

${ }^{1}$ Department of Crop and Environment Sciences, Harper Adams University, Edgmond, Newport TF10 8NB UK ${ }^{2}$ Agricultural University, Faculty of Plant Protection and Agroecology, 12 Mendeleev, str. 4000 Plovdiv, BULGARIA

Sustainable agriculture is a phrase that was rarely seen in the scientific literature before the 1990s, but since then has shown an exponential rise in usage (Figure 1).

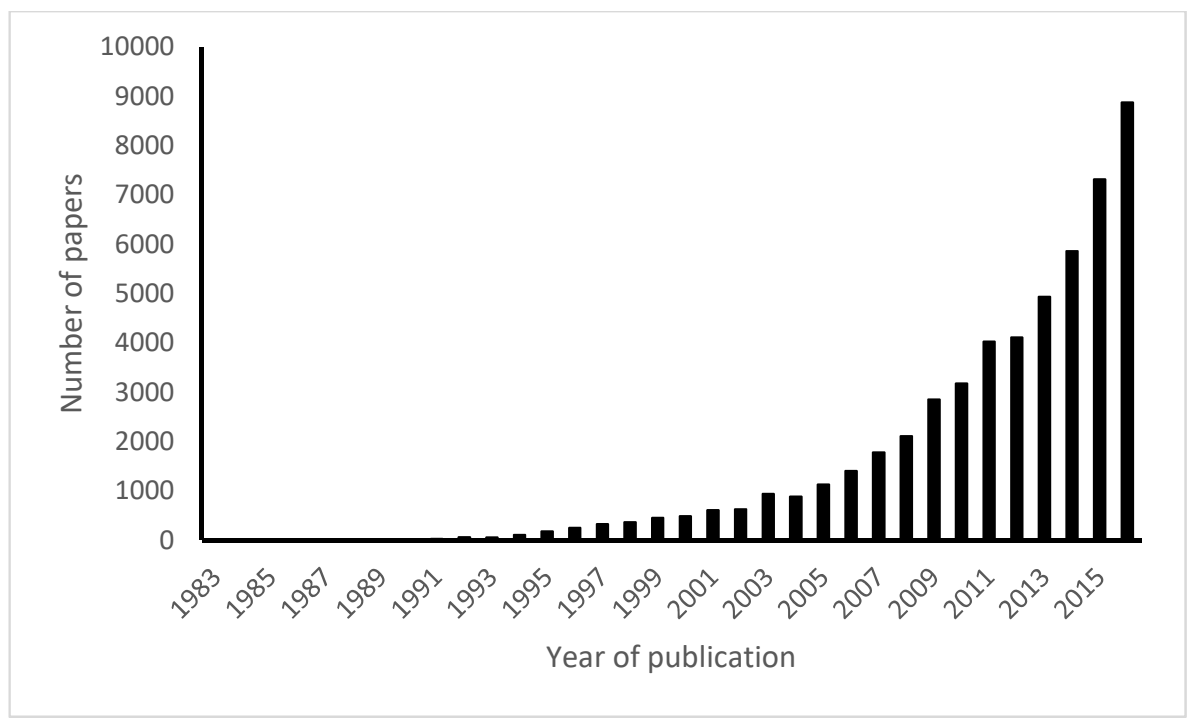

Figure 1 Papers published on sustainable agriculture since 1983 - data from Web of Science core collection

Sustainable agriculture can be defined as "a resource management strategy aimed at reducing dependence on energy-based inputs. It is based on the use of innovative soil and crop management techniques and the use of renewable inputs to attain satisfactory returns, optimize resource use, and preserve a healthy balance of soil, food, people and environment" (Lal, 1989). After inorganic fertilizers the main inputs in agriculture comes from pesticide usage (Tilman et al., 2002). One of the ways towards sustainable agricultural practice is the reduction of pesticide use by implementing appropriate integrated pest management strategies (Kogan, 1998; Suckling et al., 2014). To prevent prophylactic use of pesticides it is essential to convince growers that pesticide reduction and/or avoidance can be a profitable strategy by developing reliable economic control thresholds (Kogan, 1998). Even by the early 1970s the need for economic injury levels and thresholds was well recognised and the problems associated with their implementation well recognised (Stern, 1973). The most valuable resource needed by farmers to enable them to practice truly sustainable 
agriculture is reliable information, closely followed by access to modern technology (Nikolova, 2015).

Here we outline the problems in the development of realistic economic thresholds using two countries as exemplars, point out that lack of recent information and lack of funding further exacerbates the problem and finally, suggest ways in which thresholds could be updated.

In 2016 in the UK the six major arable crops by area were cereals, oilseed, peas and beans, potatoes and sugar beet between them covering 36013000 ha (Defra, 2016). Although control thresholds for all these crops and many more are available (AHDB, 2014) they are almost all based on data gathered many decades ago or appear to have no peer-reviewed basis (Ramsden at al., 2017). In Bulgaria the main agricultural crops by area are cereals, sunflowers oilseed rape, vegetables, alfalfa , peas and beans and potatoes covering 309955 ha between them which is very similar to the UK situation (Ministry of Agriculture and Food of Republic of Bulgaria, 2015). The situation regarding economic thresholds in Bulgaria is also similar to the UK, in that where recommendations based on economic thresholds are given (e.g. Kutinkova \& Andreev, 2004; Andreev et al., 2013) the farmer has to rely on thresholds developed more than twenty years ago (e.g Mikhailova et al., 1982; Zaharaeva et al., 1997).

The UK and Bulgaria are not alone in this state of affairs, it is a global problem. In the USA for example, the economic threshold for the aphid Sitobion avenae on wheat is as far as we can tell, based on a study from the late 1980s (Johnston \& Bishop, 1987) and in Canada a similar picture exists, such that the official site for Alberta states that many of the thresholds are nominal and unsupported by research (Alberta Agriculture and Forestry, 2014). Those that are supported by research are many decades old, and in some cases not even based on Canadian studies e.g. Kieckhefer \& Kantack (1980).

The economic injury level is based on five variables, cost of control/management, market value of the crop, injury unit per pest, damage per injury unit and proportional reduction in pest attack (Pedigo \& Higley, 1992). Each of the UK and Bulgarian major crops mentioned earlier has a suite of at least six important insect pest species attacking it at different times of year and at different phenological growth stages (Zaharaeva et al., 1997; AHDB, 2014). So in each country, for just those six main crops, we are looking at 36 different economic control and/or injury level thresholds. Given that timing of infestation and genotype (cultivar) of the plant will also affect the level and effect of the damage caused by the pest we would appear to be faced with an intractable problem, without constant research and revalidation. The financial investment in such an undertaking would be considerable, and it is one that research councils and other funding bodies appear unwilling to fund. This is a real problem, with potentially hugely damaging environmental consequences; we do not know how inaccurate the current thresholds are. For example, the original economic threshold for Sitobion avenae on cereals in the UK was published almost forty years ago (George \& Gair, 1979) when cereal varieties were approximately $50 \%$ taller than they are now. The resources allocated to grain development in modern varieties are obviously very different to that then. Does that mean the economic injury threshold is now lower or higher? Until further research is done, we can only guess based on our knowledge of whether the yield is sink limited as in barley or source limited as in wheat (Ramsden et al., 2017). Does knowing that current economic thresholds are outdated and unlikely to be a true reflection of the real yield loss, mean that farmers and agronomists should ignore them entirely and decide to spray based on their past experiences of the pests and the damage they have caused even if not on the same varieties or "play safe" and continue to use the old thresholds? There is of course a risk in adopting the latter approach as if the old threshold is now too high, the grower may be taking a risk without realising it. Another problem with existing 
thresholds, be they peer-reviewed or not, is that, with one notable exception, rice in India (Selvaraj et al., 2012), they do not usually take into account infestations by other insects.

Decision making at the farm level is complex, crop characteristics such as yield can be affected by geography, local soil conditions, nutrient status, and variety and weather conditions. A further complication is that many, if not all pests, are patchily distributed, so although one part of the field may be severely damaged, yield reduction at the whole field level may only be slight. All these can affect the potential yield and ability of a plant to tolerate damage and if all are taken into account make the determination of an economic threshold even more difficult and possibly intractable. Economic thresholds need to be reliable, easy to determine and above all, cost-effective. Coupled with this, is the ability to make an accurate assessment of the abundance of the pest(s) and a sound understanding of when in the growth cycle of the crop the assessment should be made. The need to understand crop physiology in relation to pest ecology and how this interaction changes through the crop growing cycle makes the development of new economic thresholds appear a daunting and expensive task. New technology, such as the development of robotic electronic 'noses' with the ability to assess crop volatile profiles in the field and relate these to an appropriate economic threshold, may aid in this process. Similarly, green area indices and other visual assessments of the crop may be a more important way to assess crop health rather than simply counting pests (e.g. Ward et al., 1985). Additionally it may, if reliable field data are available for single pest and disease infestations, be possible to adopt a modelling approach to predict the likely effects of multiple species on crop yields (Johnson, 1992; Willocquet et al., 2008).

Whatever the way forward, it is increasingly apparent, that for sustainable agriculture to become a global reality, new, robust economic pest threshold data are required for a great many crops across the world. It is clear, that to achieve this aim, there must be substantial investment in time, money, and people. There must also be a commitment by either governments or the agricultural industry, ideally both, to facilitate the process.

\section{Acknowledgements}

We are grateful to Tom Pope for his very useful comments.

\section{References}

AHDB (2014) Encyclopaedia of pests and natural enemies in field crops. https://potatoes.ahdb.org.uk/publications/encyclopaedia-pests-and-natural-enemies-field-crops

Alberta Agriculture and Forestry (2014) Economic thresholds for insects attacking cereals and corn. http://www1.agric.gov.ab.ca/\$department/deptdocs.nsf/all/prm2474\#25

Andreev, R., Rasheva, D. \& Kutinkova, H. (2013) Occurrence and population density of aphids in apple orchards of south Bulgaria. Journal of Plant Protection Research, 53, 353-356.

Defra (2016) Farming statistics. Final crop areas and cattle, sheep and pig populations at 1 June 2016 - England. https://www.gov.uk/government/statistics/farming-statistics-final-crop-areas-and-cattlesheep-and-pig-populations-as-at-1-june-2016-england

George, K.S. \& Gair, R. (1979) Crop loss assessment on winter wheat attacked by the grain aphid Sitobion avenae (F.). Plant Pathology, 28, 143-149. 
Johnson, K.B. (1992) Evaluation of a mechanistic model that describes potato crop losses caused by multiple pests. Phytopathology, 82, 363-369.

Kieckhefer, R.W. \& Kantack, B.H. (1980) Losses in yield in spring wheat in South Dakota caused by cereal aphids. Journal of Economic Entomology, 73, 582-585.

Kutinkova, H. \& Andreev, R. (2004) Integrated pest management in sweet cherry (Prunus avium L.) orcahrds in Bulgaria. Journal of Fruit and Ornamental Plant Research, 12, 41-47.

Johnston, R.L. \& Bishop, G.W. (1987) Economic injury levels and economic thresholds for cereal aphids (Homoptera: Aphididae) on spring-planted wheat. Journal of Economic Entomology, 80, 478482.

Kogan, M. (1998) Integrated pest management: historical perspectives and contemporary developments. Annual Review of Entomology, 43, 243-270.

Lal, R. (1989) Conservation tillage for sustainable agriculture: Tropics versus temperate environments. Advances in Agronomy, 42, 85-197.

Mikhailova, P., Straka, F. \& Apostolov, I. (1982) Rastitel'no-Zashtitna Prognoza I Signalizatsiya, Zemizdat, Sofia, Bulgaria, 344pp.

Ministry of Agriculture and food of Republic of Bulgaria (2015). Annual report on the situation and development of agriculture (Agrarian Report 2015).

http://www.mzh.government.bg/MZH/Documents/reports.aspx

Nikolova, M. (2015). Relationship between the sustainable models of production in agriculture and the challenges to their development in Bulgaria. Journal of Economics and Development Studies, 3, 57-68.

Pedigo, L.P. \& Higly, L.G. (1992) The economic injury level concept and environmental quality. American Entomologist, 38, 12-21.

Ramsden, M.W., Kendall, S.L., Ellis, S.A. \& Berry, P.M. (2017) A review of economic thresholds for invertebrate pests in UK arable crops. Crop Protection, 96, 30-43.

Selvaraj, K., Subhash, C. \& Sujithra, M. (2012) Determination of multiple-species economic injury levels for rice insect pests. Crop Protection, 32, 10-160.

Stern, V.M. (1973) Economic thresholds. Annual Review of Entomology, 18, 259-280.

Suckling, D.M., Stringer, L.D., Stephens, A.F.A., Woods, B., Williams, D.G., Baker, G., \& El-Sayed, A.M. (2014) From integrated pest management to integrated pest eradication: technologies and future needs. Pest Management Science, 70, 179-189.

Tilman, D., Cassman, K.G., Matson, P.A., Naylor, R. \& Polasky, S. (2002) Agricultural sustainability and intensive production practices. Nature, 418, 671-677.

Ward, S.A., Rabbinge, R., \& Mantel, W.P. (1985) The use of incidence counts for estimation of aphid populations 1 Minimum sample size for required accuracy. Netherlands Journal of Plant Pathology, 91, 93-99. 
Willocquet, L., Aubeot, J.N., lebard, S., Robert, C., Lannou, C. \& Savary, S. (2008) Simulating multiple pest damage in varying winter wheat production situations. Field Crops Research, 107, 12-28.

Zahareva, T., Krasteva, H., Grigorov, P., Nikolov, N. Atanasov, N. \& Volkov, G. (1997) Economic injury Levels for the Main Pests on Agricultural Crops. National Service of Plant Protection, Quarantine and Agrochemistry, Sofia, $23 \mathrm{pp}$. 